\title{
Interphotoreceptor Retinoid-Binding Protein (IRBP) in Retinal Health and Disease
}

\author{
Shaoxue Zeng ${ }^{1,2}$, Ting Zhang ${ }^{1 *}$, Michele C. Madigan ${ }^{1,3}$, Nilisha Fernando ${ }^{4}$, \\ Riemke Aggio-Bruce ${ }^{4,5}$, Fanfan Zhou ${ }^{6}$, Matthew Pierce ${ }^{1}$, Yingying Chen ${ }^{1,2}$, \\ Lianlin Huang ${ }^{1,3}$, Riccardo Natoli ${ }^{4,5}$, Mark C. Gillies ${ }^{1}$ and Ling Zhu ${ }^{1}$ \\ ${ }^{1}$ Save Sight Institute, The University of Sydney, Sydney, NSW, Australia, ${ }^{2}$ Department of Ophthalmology, West China \\ Hospital, Sichuan University, Chengdu, China, ${ }^{3}$ School of Optometry and Vision Sciences, University of New South Wales, \\ Sydney, NSW, Australia, ${ }^{4}$ The John Curtin School of Medical Research, The Australian National University, Acton, ACT, \\ Australia, ${ }^{5}$ The Australian National University Medical School, The Australian National University, Acton, ACT, Australia, \\ ${ }^{6}$ Sydney Pharmacy School, The University of Sydney, Sydney, NSW, Australia
}

Interphotoreceptor retinoid-binding protein (IRBP), also known as retinol binding protein 3 (RBP3), is a lipophilic glycoprotein specifically secreted by photoreceptors. Enriched in the interphotoreceptor matrix (IPM) and recycled by the retinal pigment epithelium (RPE), IRBP is essential for the vision of all vertebrates as it facilitates the transfer of retinoids in the visual cycle. It also helps to transport lipids between the RPE and photoreceptors. The thiol-dependent antioxidant activity of IRBP maintains the delicate redox balance in the normal retina. Thus, its dysfunction is suspected to play a role in many retinal diseases. We have reviewed here the latest research on IRBP in both retinal health and disease, including the function and regulation of IRBP under retinal stress in both animal models and the human retina. We have also explored the therapeutic potential of targeting IRBP in retinal diseases. Although some technical barriers remain, it is possible that manipulating the expression of IRBP in the retina will rescue or prevent photoreceptor degeneration in many retinal diseases.

Keywords: IRBP gene, photoreceptor degeneration, visual cycle, gene therapy, retinoid

\section{INTRODUCTION}

\section{A Brief History of IRBP}

Interphotoreceptor retinoid-binding protein (IRBP), also known as retinol binding protein 3 (RBP3), was first discovered in soluble proteins extracted from the bovine interphotoreceptor matrix (IPM), which is located between the neural retina and the retinal pigment epithelium (RPE) (Adler and Severin, 1981). Several unknown proteins were identified, including a 140 kilodalton $(\mathrm{kDa})$ protein (Liou et al., 1982). Liou et al. suggested that this $140 \mathrm{kDa}$ protein might be a transporter protein transferring retinol between the outer segments of rod photoreceptors and the RPE (Liou et al., 1982). They postulated that the molecular weight of IRBP is $260 \mathrm{kDa}$ in its glycosylated form, while its backbone is $140-145 \mathrm{kDa}$ (Liou et al., 1982).

In the 1990's, several studies implicated IRBP in retinal development (Gonzalez-Fernandez et al., 1993; Timmers et al., 1993; Liou et al., 1994; Stenkamp et al., 1998). The messenger RNA (mRNA) expression of IRBP in the retina of embryonic mice was low. mRNA transcripts in mice were first detected at embryonic day 11 and continued to increase to its peak expression on postnatal day 4, after which there was a slow decrease and reached constancy by postnatal day 20 (Liou et al., 1994). 
The protein expression of IRBP increased together with its mRNA level during photoreceptor development in bovine and zebrafish embryos (Timmers et al., 1993; Stenkamp et al., 1998). Protein and mRNA expression were also markedly increased in Sprague Dawley rats between postnatal day 1 and 9, a period critical for outer segment formation. Then, IRBP mRNA levels decreased a little and stabilized by postnatal day 20 when the outer segments achieved their adult length (Gonzalez-Fernandez et al., 1993).

IRBP has been shown to be downregulated in animal models of retinal disease, including Abyssinian cats that carry a homozygous IRBP mutation that causes pan-retinal degeneration (Narfstrom et al., 1989). IRBP downregulation has also been reported in mice with induced Müller cell dysfunction and a streptozotocin (STZ)-induced diabetic rat model (Zhu et al., 2015; Malechka et al., 2017). IRBP deficiency also impaired eye growth and compromised retinal health in mice (Wisard et al., 2011). These reports suggest a correlation between IRBP dysregulation and photoreceptor degeneration.

\section{Retinal Location of IRBP}

IRBP is secreted by photoreceptors and accumulates in the IPM to facilitate the transport of material for visual pigment regeneration (Ishikawa et al., 2015) (Figure 1a). It has only been found in vertebrates (Kusakabe et al., 2009). In the eyes of non-vertebrates, an alternative mechanism of pigment regeneration is confined to photoreceptors (Kusakabe et al., 2009). Vertebrates acquired IRBP in the evolution of the visual cycle to accommodate a complicated visual cycle. IRBP can traffick retinoid, a class of Vitamin A derivatives that includes retinol and retinal, between photoreceptors and RPE cells (Kusakabe et al., 2009). IRBP mRNA was detected in both cones and rods of adult Xenopus retina. However, IRBP in the embryo is synthesized by the central retina and diffuses through the matrix, reaching the peripheral retina (Hessler et al., 1996).

Theo and colleagues found IRBP in bovine pineal gland cells by in situ hybridization using IRBP cDNA probes. They discovered that IRBP is highly expressed in a population of pineal cells on mRNA level, but they did not quantify its protein expression (van Veen et al., 1986). Expression of IRBP (Rodrigues et al., 1986), cone arrestin (Craft et al., 1994) and opsins (Blackshaw and Snyder, 1997), all photoreceptors markers, were also found in the pineal gland of Rhesus monkeys, rats and catfish. It remains unclear why there is a morphological and possibly functional analogy between photoreceptors and pinealocytes. The pineal gland, a small neuroendocrine organ that synthesizes and secretes melatonin, is also photosensitive in lower vertebrates (Sapède and Cau, 2013). Some researchers have hypothesized that mammalian pinealocytes might have evolved from photoreceptors (Sapède and Cau, 2013).

\section{Molecular Characteristics and Regulation of IRBP}

Mammals have four protein subunits of IRBP (GonzalezFernandez, 2012), each of which consists of $\sim 300$ amino acids (Nickerson et al., 2006). Two of the four subunits are similar but have different affinities to all-trans-retinol. Notably, disrupting one subunit does not affect the overall function because other subunits compensate for the dysfunctional subunit (GonzalezFernandez and Ghosh, 2008).

The IRBP gene is regulated by cone-rod-homeobox (CRX) and orthodenticle homolog 2 (OTX2), two essential transcriptional factors in photoreceptors (Fei et al., 1999; Nishida et al., 2003) (Figure 1b). Studies have suggested that the "cone-rod-homeobox element" is essential for the photoreceptorspecific activity of the IRBP promoter in vivo. This element is the major binding site of the CRX, which can directly regulate IRBP expression (Fei et al., 1999). OTX2 is an upstream regulator of CRX. Both OTX2 and CRX mRNAs have been identified in adult human retinas (Bobola et al., 1999; Nishida et al., 2003; Li et al., 2015). Overexpressing OTX2 increased irbp promoterluciferase activity by $5-7$-fold in WERI-Rb1 retinoblastoma cells, suggesting that OTX2 activates the irbp promoter (Bobola et al., 1999). Overall, CRX and OTX2 are both specific gene regulators of IRBP that are critical in photoreceptor development.

\section{IRBP IN THE NORMAL RETINA}

\section{Retinoids Transport}

Retinoid recycling and metabolism within the eye have been extensively studied for decades. George Wald was awarded a Nobel prize in 1967 for discovering the photoreceptive proteins in the eye, the "chromoproteins" (Wald, 1935). Vision is initiated and maintained by their photolysis and regeneration in the visual cycle (Kiser et al., 2014). Photolysis of 11-cis-retinal is the only reaction that converts light signals into electrical signals in vertebrate photoreceptors (Molday and Moritz, 2015). Circulation and regeneration of 11-cis-retinal, which relies on IRBP for its transport, is critical for the maintenance of light sensitivity (Liou et al., 1998; Jin et al., 2009). Thus, IRBP is central to developing and maintaining the visual cycle in humans.

\section{The Canonical Visual Cycle}

In the canonical visual cycle (Figure 2A), IRBP is secreted into the IPM by photoreceptors and rapidly turned over through endocytosis by photoreceptors and the RPE (GonzalezFernandez, 2003). It mediates extracellular diffusion of retinoids during the operation of the retinoid cycle, transporting alltrans-retinol and 11-cis-retinal between the photoreceptors and the RPE (Gonzalez-Fernandez, 2003). A recent study suggested that IRBP may not be the only vehicle and peropsin may also transport all-trans-retinol from the neural retina to RPE (Cook et al., 2017). Human organic anion transporting polypeptide 1A2 (OATP1A2) has been recently found to be expressed at the apical membrane of RPE, where it facilitates the cellular uptake of all-trans-retinol into the RPE cells (Chan et al., 2015).

IRBP is essential for retinoid exchange in the visual cycle. Exogenously applying IRBP protein to the culture medium of rod photoreceptors reduced the level of all-trans-retinal and retinol in outer segments, preventing the formation of light-induced lipofuscin precursor (Chen et al., 2017). Supplementation of IRBP in the culture medium also facilitates the release of 11cis-retinal from cultured fetal bovine RPE cells (Carlson and Bok, 1992). Addition of the free form IRBP to the RPE apical 


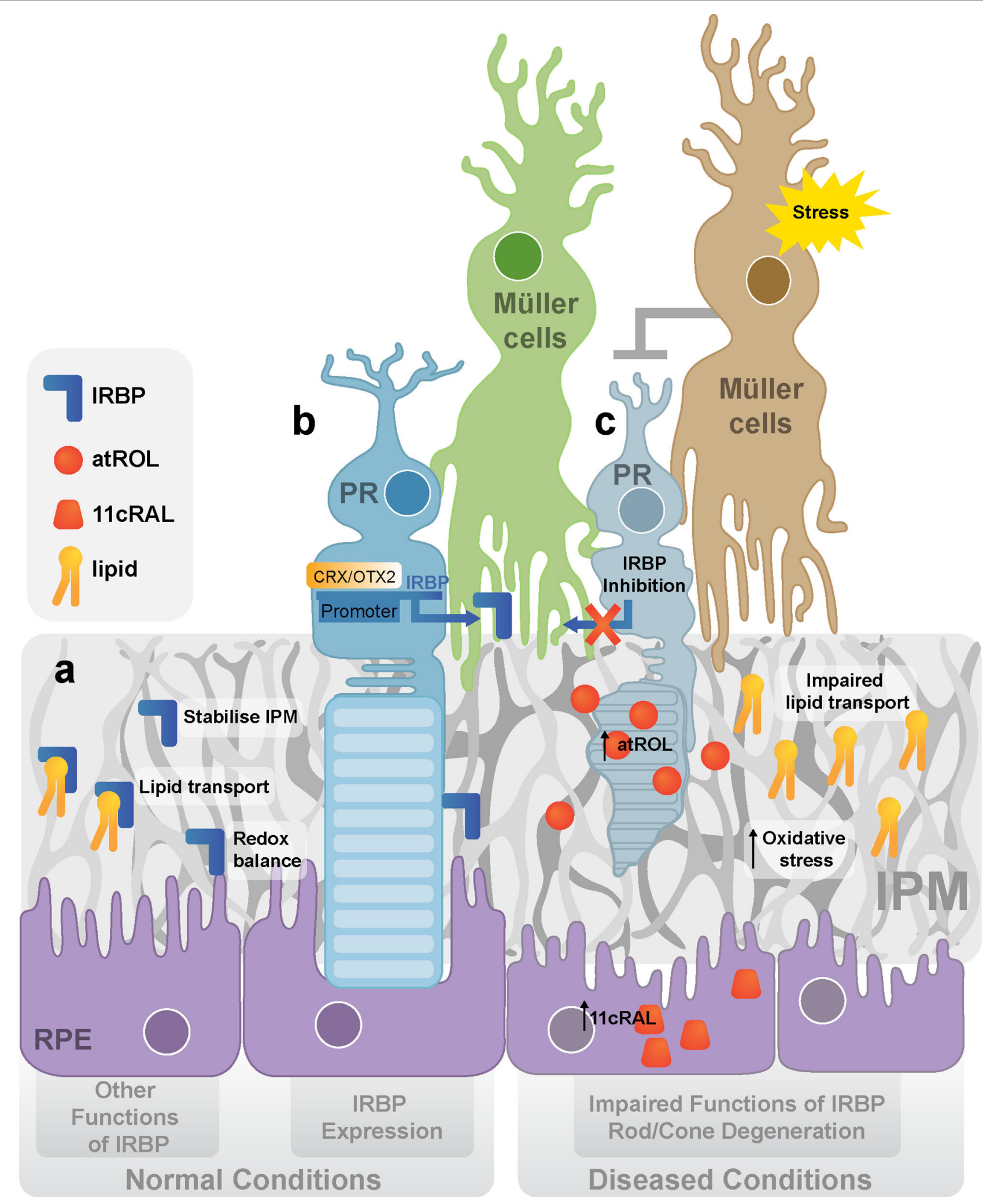

FIGURE 1 | IRBP in normal and diseased retina. (a) The expression and functions of IRBP. IRBP is produced and secreted by photoreceptors. The main function of IRBP is to stabilize IPM, transport lipid between photoreceptors and the RPE and maintain the redox balance in the outer retina. (b) The regulation of IRBP. OTX2/CRX activates the expression of IRBP by binding to its promoter. (c) IRBP dysregulation and rod/cone degeneration under stress. It is proposed that stress 
FIGURE 1 | activates Müller cells inhibiting the production of IRBP in photoreceptors, leading to the dysfunction of lipid transport, increased oxidative stress, and accumulation of retinoids (atROL). (IRBP, Interphotoreceptor retinoid-binding protein; CRX, cone-rod-homeobox; OTX2, orthodenticle homolog 2; IPM,

interphotoreceptor matrix; RPE, retinal pigment epithelium; PR, photoreceptor; atROL, all-trans-retinol; 11cRAL, 11-cis-retinal).

membrane resulted in more $[3 \mathrm{H}]-11$-cis-retinal release than adding cellular retinaldehyde-binding protein (CRALBP), serum retinol-binding protein (RBP), bovine serum albumin (BSA) or medium devoid of binding proteins (Carlson and Bok, 1992). Light reduced the levels of 11-cis-retinol when IRBP was absent, while it had no effect on 11-cis-retinol levels if IRBP was present. These results indicate IRBP is essential in preserving the isomeric state of retinol (Parker et al., 2011).

\section{The Cone-Specific Visual Cycle}

The cone-specific visual cycle (Figure 2B) refers to the exclusive ability of cone photoreceptors and Müller cells to convert alltrans-retinol to 11-cis-retinal (Wang and Kefalov, 2009; Sato and Kefalov, 2016). In contrast to the canonical visual cycle, all-transretinol is transported to Müller cells, facilitated by IRBP (Mata et al., 2002). IRBP was implicated by the observation that it promoted the uptake of all-trans-retinol and release of 11 -cis retinol in rat Müller cells in vitro (Betts-Obregon et al., 2014). Cone electroretinogram (ERG) responses in IRBP knockout mice were reduced compared to that of the control mice, although they had similar cone densities and opsin levels, indicating IRBP is essential for normal cone function or at least for the cone-specific vision cycle (Parker and Crouch, 2010). Müller cells have been found to isomerise all-trans-retinol directly to 11-cis-retinol, which then released for cone photoreceptors (Crouch et al., 1992; Das et al., 1992). Finally, the cone photoreceptor outer segments have been reported to oxidize 11-cis-retinol to 11-cis-retinal (Jones et al., 1989). Recently, further evidence has also implicated IRBP in the retinoid exchange between cones and Müller cells (Tang et al., 2013). IRBP was found to bind to the cone outer segment and Müller cell microvilli pericellular matrices (Garlipp and Gonzalez-Fernandez, 2013). This association can facilitate the delivery and uptake of its retinol ligands.

\section{Lipid Transport}

Apart from retinoid transportation, IRBP assists the transport of various essential lipids across the IPM (Figure 1a). It has been established that IRBP contains two similar subunits with different affinities for all-trans-retinol. Long-chain fatty acids, such as Docosahexaenoic Acid (DHA), can replace all-trans-retinol from these subunits with lower affinity (Chen et al., 1993). DHA is an essential element in photoreceptor membrane biosynthesis and is thus vital for visual function in photoreceptors (Scott and Bazan, 1989; Jastrzebska et al., 2011). Post-mortem AMD retina and RPE/choroid were reported to have significantly lower levels of polyunsaturated fatty acids, such as DHA, than agematched normal donors, suggesting the importance of IRBP to photoreceptors by transporting DHA or other fatty acids (Liu et al., 2010) (Figure 1c).

Other studies also demonstrated that other fatty acids could also compete with all-trans-retinol for binding IRBP, among which oleic acid had the highest affinity, but it was still significantly lower than that of all-trans-retinol (Semenova and Converse, 2003; Ghosh et al., 2015). A fluorometric titration experiment in which increasing the concentrations of oleic acid gradually reduced the affinity of all-trans-retinol to IRBP provided further evidence that IRBP plays a vital role in lipid transport (Ghosh et al., 2015). Competitive fluorescence and tryptophan-quenching assays also demonstrated that both oleic acid and DHA could displace all-trans-retinol from bovine IRBP, while oleic acid having a relatively higher affinity than DHA. Gas chromatography revealed that oleic acid is the most abundant fatty acid in bovine IPM, suggesting it might play an important role in maintaining the balance and transport of retinoids and fatty acids in the retina (Semenova and Converse, 2003).

\section{Important Roles of IRBP in IPM Integrity}

The IPM, a highly organized structure between photoreceptors and the RPE, is essential for maintaining outer retinal homeostasis. Characteristic changes in IPM components occur in retinal degenerations (Ishikawa et al., 2015). For example, photoreceptor degeneration in most retinal diseases begins with the loss of the inner segments/outer segments in the IPM. However, photoreceptors may still survive under these circumstances (Goldberg et al., 2016).

IRBP accounts for $\sim 5 \%$ of the total soluble IPM protein (Adler and Evans, 1983) and maybe crucial for the structural integrity of the IPM (Figure 1a). Although a large amount of IRBP can be removed by washout with a saline solution, other wash-resistant IRBP that co-localizes in the IPM is concentrated around cone outer segments (cone IPM-associated IRBP) (Garlipp and Gonzalez-Fernandez, 2013). Furthermore, the deduced amino acid sequence of human IRBP contains two receptors for hyaluronan-mediated motility (RHAMM)like motifs (K321-R329 and K733-R781), suggesting a possible interaction of IRBP with the hyaluronan scaffold (Hollyfield, 1999), a component of non-covalently formed complexes with proteoglycans in the Extracellular Matrix (ECM). Thus, IRBP dysregulation is likely to affect the structural integrity of IPM, which may independently contribute to the development of many retinal diseases.

\section{Antioxidant Activity of IRBP}

IRBP has a thiol-dependent antioxidant activity which may protect retinol from oxidation (Figure 1a). The thiol-dependent antioxidative activity of IRBP has been evaluated with an assay using myoglobin and 2,2-azinobis (3-ethylbenzothiazoline-6sulfonic acid) (ABTS). IRBP was found to inhibit the oxidation of ABTS more actively than other free thiol groups or thiolbased reducing enzymes such as thioredoxin, vitamin $\mathrm{E}$ analog Trolox, and ovalbumin. Using N-ethylmaleimide (NEM) to inhibit cysteine peptidases by alkylating the active site-thiol on 


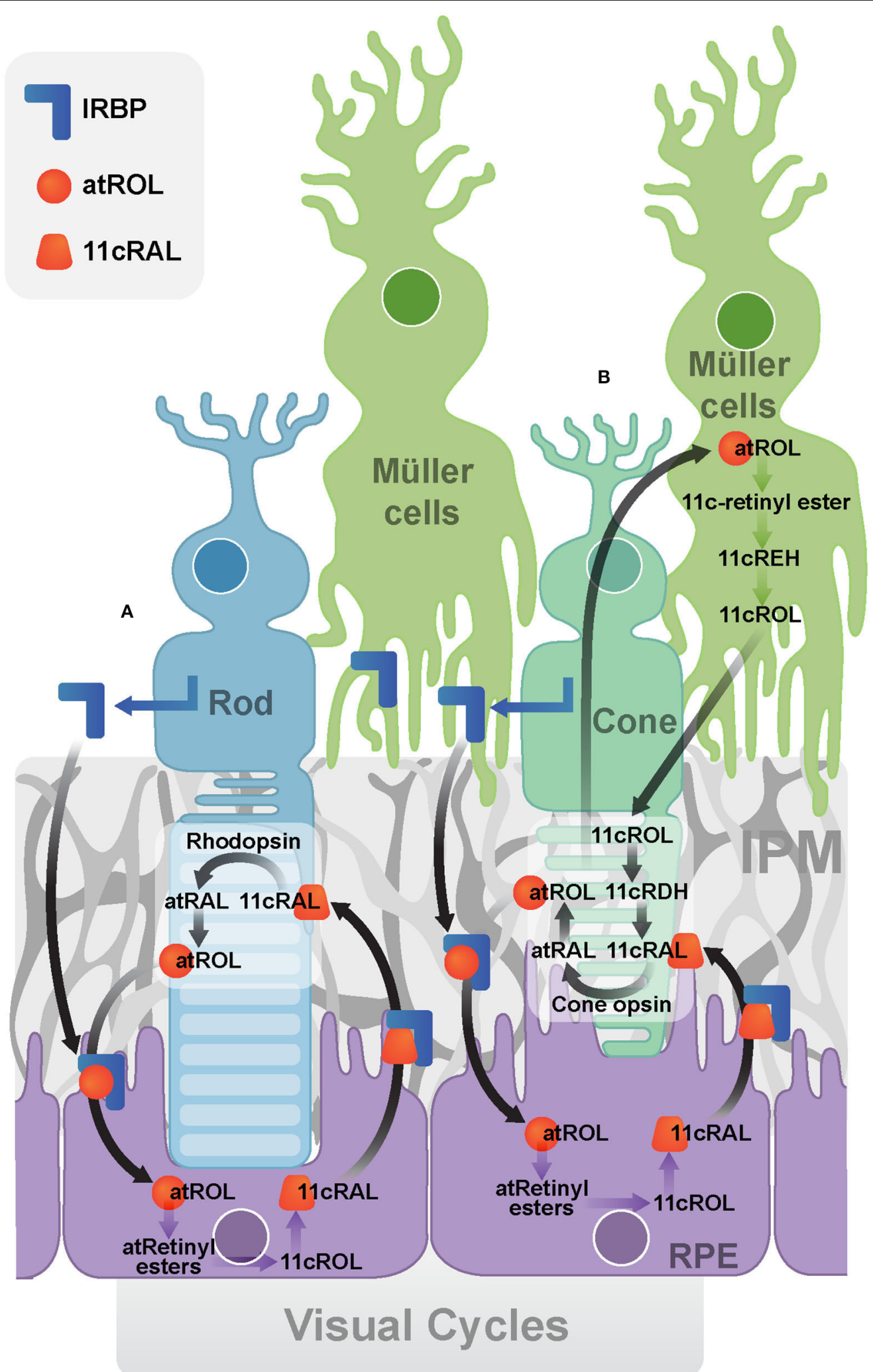

FIGURE 2 | Visual Cycles. (A) The canonical visual cycle. IRBP facilitates the transport of retinoids (atROL and 11cRAL) between photoreceptors and the RPE. (B) The cone-specific visual cycle between cone photoreceptors and Müller cells. (IRBP, Interphotoreceptor retinoid-binding protein; IPM, interphotoreceptor matrix; RPE, retinal pigment epithelium; atRAL, all-trans-retinal; atROL, all-trans-retinol; 11cRAL, 11-cis-retinal; 11cROL, 11-cis-retinol; 11cRDH, 11-cis-retinol dehydrogenase; 11cREH, 11-cis-Retinyl ester hydrolase). 
IRBP also suppressed the antioxidant capacity of IRBP. Thus IRBP contains a thiol-dependent antioxidant site, disruption of the putative ligand-binding site can lead to reduced antioxidant effects (Gonzalez-Fernandez et al., 2014) (Figure 1c).

All-trans-retinal causes severe cellular oxidative stress and leads to reactive oxygen species (ROS) accumulation, mitochondrial dysfunction and cell death (Maeda et al., 2009; Chen et al., 2012; Rózanowska et al., 2012). Levels of all-transretinal were significantly higher in the retinal explants of IRBP knockout mice than that in wild type mice after 40 min exposure to bright light. This phenomenon was significantly mitigated by adding IRBP in the culture medium (Lee et al., 2016).

\section{IRBP IN RETINAL DISEASES}

\section{IRBP in Animal Models of Retinal Disease}

Extensive animal studies have shown that IRBP downregulation occurs in the early stages of many various retinal diseases. In fact, it may be a precursor to them (Zhu et al., 2015; Malechka et al., 2017). In 1989, a reduction of IRBP was reported in the early stages of retinal degeneration in a model of Abyssinian cats which carry a homozygous mutation for retinal degeneration (Narfstrom et al., 1989). A mutation in intron 50 of the centrosomal protein 290 (CEP290) gene (IVS50 + $9 \mathrm{~T}>\mathrm{G}$ ) induced a stop codon and truncation of the mature protein in this model (Menotti-Raymond et al., 2007). IRBPimmunoreactivity was significantly reduced in the affected retina prior to the development of photoreceptor cell death (Narfstrom et al., 1989). In the same model, mRNA and protein levels of IRBP were significantly reduced as early as 4 weeks of age (Wiggert et al., 1994). Downregulation of IRBP protein was also found in a retinal degeneration 12 (rd12) mouse model with a mutation in the RPE65 gene (Zheng et al., 2015). We have previously described this in a mouse model in which Müller cell dysfunction can be induced. A $150 \mathrm{kDa}$ protein band was markedly diminished in the transgenic mice retina just 1 week after the Müller cells were disrupted, which was identified as IRBP by mass spectrometry. Photoreceptor degeneration was observed 2 weeks after the Müller cell disruption was induced in this transgenic model, suggesting that photoreceptor degeneration was secondary to Müller cell disruption (Zhu et al., 2015). It was also reported that the IRBP protein level was significantly reduced in the retinas of STZ-induced diabetic rats (Malechka et al., 2017). It has also been reported that IRBP mRNA was reduced in a light-induced retinal degeneration model in rats after animals had been exposed to intense visible light (490$580 \mathrm{~nm}$ green light) with an illuminance of $\sim 1,200$ lux for $24 \mathrm{~h}$ to induce photoreceptor degeneration (Wong et al., 2001). Overall, the early reduction of IRBP in different models of retinal degeneration suggests that IRBP may be a primary defect or an early disease marker in the retina.

IRBP dysregulation has been widely observed in different models of retinal disease. However, the consequences of IRBP downregulation on retinal or ocular health remains poorly understood. Studies on IRBP knockout models have identified an essential role of IRBP in eye growth and retinal health (Wisard et al., 2011; Markand et al., 2016). Eyes of IRBP knockout mice increased in size and weight over the wild type controls even before the mice had opened their eyelids (Wisard et al., 2011). Mice lacking IRBP display severe early and progressive photoreceptor degeneration, characterized by a reduction in both length and numbers of cone sheaths (Sato et al., 2013). IRBP knockout mice also developed profound myopia during the early stages of eye development. These eyes had longer anterior-posterior length, accompanied by a decrease in hyperopic refractive error (Markand et al., 2016). Progressive thinning of the outer nuclear layer was evident, with $20 \%$ thinning observed at postnatal day 5 , and $38 \%$ thinning at day 30. Further studies, using optical coherence tomography (OCT), confirmed the previously reported retinal thinning of the outer nuclear layer in the IRBP knockout mice. Thinning of the outer nuclear layer lasted from postnatal day 15 to at least postnatal day 80 compared to wild type mice. Additionally, the slit-lamp and fundus photographs found no difference between the wild type and knockout mice (Markand et al., 2016). Another study on IRBP knockout mice revealed a loss of photoreceptor nuclei and changes in the structural integrity of retinas at postnatal day 11 and a marked loss in photic sensitivity from Electroretinography (ERG) at postnatal day 30 (Liou et al., 1998).

In summary, IRBP downregulation has been described in photoreceptors in different retinal diseases, but the precise mechanism for IRBP downregulation is still not clear. One possible explanation is that IRBP is a high molecular weight glycoprotein, the synthesis of which requires the production of large amounts of molecular building blocks and consumes a considerable amount of energy. Reduction of photoreceptor metabolism and the visual cycle may be necessary for the retina to survive under stress. Downregulation of IRBP may be beneficial for retina with short-term stress, but it might cause retinal degeneration if stress is persistent.

\section{IRBP and Human Retinal Diseases}

It has been established that mutation, dysfunction or downregulation of IRBP can be found in several human eye diseases. For instance, a homozygous missense mutation (p.Asp1080Asn) of IRBP was observed in a pedigree of four patients with autosomal recessive retinitis pigmentosa (RP) (den Hollander et al., 2009). Non-sense mutations (c.1530T>A;p.Y510* and c.3454G > T;p.E1152*) in IRBP were identified in four children diagnosed with retinal dystrophy and myopia (Arno et al., 2015). OCT images of these patients showed thinning of the central macula and loss of the inner segment ellipsoid band. ERG also revealed a delay and amplitude reduction in cone-specific responses (Arno et al., 2015). Li's group showed that D1080N mutation in IRBP found in patients with RP, abolished the secretion of IRBP and resulted in the formation of insoluble high molecular weight complexes via disulphide bonds. This hindered the transportation of IRBP to the Golgi and caused endoplasmic reticulum (ER) stress, which suggested another mechanism of retinal degeneration caused by IRBP mutation. A heterozygous T-C transition has been identified in autosomal recessive retinitis pigmentosa. IRBP protein was at a significantly lower level in aqueous humor of primary congenital glaucoma patients (Li et al., 2013). Reduced 
IRBP mRNA and protein expression were observed in the retinas from diabetic donors when compared with those from non-diabetic donors (Garcia-Ramirez et al., 2009). Analysis of vitreous fluid obtained from clinics revealed that IRBP levels were reduced in the early stages of diabetic retinopathy (GarciaRamirez et al., 2009). Vitreous IRBP concentration declined gradually with the increasing severity of diabetic retinopathy in eyes with established retinopathy. IRBP protein levels both in the retina and vitreous of eyes with non-proliferative diabetic retinopathy were higher than those with proliferative diabetic retinopathy (Yokomizo et al., 2019).

Downregulation of IRBP also caused the accumulation of the retinal 'waste product' lipofuscin, which may increase the risk of oxidative damage to the RPE and photoreceptors (Radu et al., 2003) (Figure 1c). Lipofuscin is also responsible for retinal autofluorescence in retinal diseases (Birnbach et al., 1994; Marmorstein et al., 2002; Radu et al., 2003). Studies on cryosections of human retinas with AMD have revealed that lipofuscin in the RPE was strongly autofluorescent (Marmorstein et al., 2002). Stargardt's disease is characterized by hyperautofluorescence and loss of macular photoreceptors which have been correlated with clinical progression of the disease (Birnbach et al., 1994).

We have discussed IRBP dysregulation as an early disease indicator, playing a role in the early stages of retinal pathology. Further studies are required to elucidate all of the mechanisms by which IRBP dysfunction may contribute to retinal disease pathogenesis.

\section{Autoantibodies to IRBP}

The retina is an 'immune-privileged' site, which means it may tolerate the introduction of antigens without eliciting an inflammatory immune response (Benhar et al., 2012). This presumably protects the retina from potentially blinding processes such as fibrosis that may result from inflammation. The blood-retinal barrier (BRB) is the interface between systemic circulation and the retina, which is critical for the maintenance of this immune-privilege (Benhar et al., 2012). Breakdown of the BRB, which occurs in many retinal diseases, exposes retinal antigens to the immune system, eliciting an inflammatory response leading to tissue damage and vision loss (Chen et al., 2019).

IRBP peptides can induce experimental autoimmune uveitis, which is a well-estblished model of uveitis (Caspi et al., 1990), as well as the effects of the adaptive immune response in the eye (Agarwal et al., 2012; Kyger et al., 2013). Anti-IRBP autoantibodies have been found in patients with uveitis, RP, Coats disease, AMD and Macular Telangiectasia Type 2 (MacTel) (Solomon et al., 1999; Morohoshi et al., 2012; Kyger et al., 2013; Zhu et al., 2013; Gibbs et al., 2017). A study investigated the autoimmune condition of a girl with a rare triad of RP, Coats disease and uveitis, and found that her peripheral lymphocytes had a specific anamnestic response to IRBP (Solomon et al., 1999), indicating that autoimmunity toward IRBP might play a role in the degeneration of photoreceptors. The IRBP autoantibody was detected in $28 \%$ (5 out of 18 ) of patients with non-infectious uveitis (Gibbs et al., 2017), in 33\% (6 out of 18) of patients with AMD and in 24\% (11 out of 45) of those with MacTel (Zhu et al., 2013). The detection of IRBP autoantibodies in these patients suggested that such diseases may share some common etiological or pathogenic mechanisms (Zhu et al., 2013). Significant downregulation of IRBP protein expression was also detected in the retina of mice with induced Müller cell dysfunction, which is a model of primary Müller cell loss that has been implicated in the pathogenesis of MacTel (Zhu et al., 2015). Whether these autoantibodies actually cause the reduction of IRBP or whether they are an epiphenomenon is still uncertain, but it appears certain that loss of IRBP is closely related to many retinal diseases.

\section{THE POTENTIAL APPLICATIONS OF IRBP IN TREATMENT FOR RETINAL DISEASES}

IRBP could be a potential novel target in treating retinal diseases, considering its essential role in the maintenance of the visual cycle and other physiological functions in the IPM (Gonzalez-Fernandez et al., 2014; Ghosh et al., 2015; Chen et al., 2017). The upregulation of IRBP prevented photoreceptor degeneration in diabetic mice and rats through the regulation of VEGF (Yokomizo et al., 2019). This data indicates that IRBP may also be beneficial in other diseases characterized by photoreceptor degeneration and VEGF dysregulation, such as AMD. Downregulation or dysregulation of IRBP could disrupt the visual cycle which leads to the accumulation of the all-transretinal, one component of retinal "waste product" lipofuscin. The effect of IRBP on preventing lipofuscin accumulation could be central for AMD-like diseases (Radu et al., 2003) (Figure 1c). Direct upregulation of IRBP through inducing the whole IRBP gene (9.5 k base pairs) warrants further investigation, but the difficulty is that the genetic constructs required would exceed the packing capacity of traditional adenovirus carriers for gene therapy. The insert size could be even longer after adding additional cell-specific promoters such as promoter fragments of cone transducin $\alpha(\mathrm{T} \alpha \mathrm{C})$, rhodopsin kinase (GRK1) or cone arrestin (CAR) gene (Kennedy et al., 2007; McDougald et al., 2019) for target-specific expression in photoreceptors. Here, we discuss three alternative ways to upregulate IRBP expression (small molecules, microRNAs, and CRISPRa technique), which we anticipate will protect photoreceptors from degeneration.

\section{Small Molecules}

Chemical communication mediated by molecular signaling coordinates cell behavior (Buddingh et al., 2020). Many natural or synthetic chemical compounds which regulate different metabolic or signaling pathways have great therapeutic potential. Small molecules that have the antioxidant, anti-inflammatory and anti-excitotoxic capacity in the central nervous system can be administered to protect photoreceptors (Zhang et al., 2019). For example, simvastatin is a cholesterol-lowering drug and was recently reported to protect Y79 retinoblastoma cells which have many characteristics of photoreceptors, through upregulating IRBP and its transcription factor CRX (Zhang et al., 2019). Some other small molecules acting on the 
cardiovascular system may also have a neuroprotective effect on photoreceptors (Zhao et al., 2016). Tetramethylpyrazine, which has been widely used in treating cardiovascular diseases for over 40 years, was found to attenuate all-trans-retinal -induced cytotoxicity in the differentiated Y79 cells via suppressing oxidative and nitrosative stress, apoptosis and leukostasis (Zhao et al., 2016). A further study found that the neuroprotective effect of tetramethylpyrazine against all-trans-retinal toxicity is also mediated through upregulating IRBP expression (Wang et al., 2017). Therefore, some small molecules have the potential to protect photoreceptors from stress by increasing IRBP expression.

Small molecules, however, have several shortcomings. Firstly, the downstream signaling cascade reactions and information encoding may vary broadly with different concentrations of signaling molecules (Purves and Fitzpatrick, 2001). Thus, the optimal dosage must be precisely controlled. Also, the enormous quantity of small molecules makes it difficult to find the desired molecule accurately. A luciferase reporter system may overcome this drawback (Xie et al., 2016). The luciferase reporter system can be specifically designed to screen small molecules that upregulate IRBP expression. By inserting the promoter region of human IRBP gene into the luciferase reporter plasmid, small molecules that specifically bind to this promoter region can be identified from the luciferase reporter activity (Miraglia et al., 2011). However, it is difficult to disentangle the downstream signaling through which the candidate small molecules regulate the expression of IRBP. Some molecules acting on Müller cells may also modulate IRBP expression via complex glianeuron interactions (Vecino et al., 2016). Low specificity, low efficiency and the short-acting time of small molecules also pose a formidable challenge to their successful application (Maxim et al., 2014). A sustained-release formulation is highly desirable in this case. Nanoparticles introduced in the vitreous may sustain the delivery of the encapsulated agents for longer durations (Kompella et al., 2003; Riley and Vermerris, 2017). For example, Anti-VEGF aptamer EYE001 (tested in humans for efficacy) entrapped in Poly lactic-co-glycolic acid (PLGA) microspheres were found to deliver EYE001 in a sustained manner with retained activity in vitro and ex vivo (Carrasquillo et al., 2003). Lipid nanoparticle approaches with specific and sustained delivery systems are expected to gain more attention in the future. Several other studies have also demonstrated the successful application of nanoparticles in the liver with approval by the US Food and Drug Administration (FDA) (Coelho et al., 2013; Rizk and Tuzmen, 2017).

Therefore, the successful clinical application of synthetic and natural compounds may provide advantages but will present challenges.

\section{MicroRNAs}

A microRNA is a small non-coding RNA that can regulate gene expression of complementary mRNAs by binding to the $3^{\prime}$ untranslated region (3' UTR) (Ambros, 2004; Bartel, 2018). More than $60 \%$ of protein-encoding genes are controlled by microRNAs (Friedman et al., 2009). It is recognized that microRNAs play an important role at the post-transcriptional level through degradation and translational repression of their target mRNAs (He and Hannon, 2004). Since the first study in 1993 discovering these post-transcriptional RNA-RNA interactions, microRNAs have attracted lots of attention due to their powerful post-transcriptional role, small size (21 nt), ease of transfection and ability for a single miRNA to regulate whole gene pathways (Lee et al., 1993; Wightman et al., 1993; Filipowicz et al., 2008). 320 and 340 different kinds of microRNAs have been found in mouse retina and RPE/choroid, respectively (Soundara Pandi et al., 2013). Despite miRNA being suggested as being involved in retinal degenerations, no studies have looked at the role of miRNA regulation on IRBP.

Computational analysis using target scan (http://www. targetscan.org/vert_72/) (Agarwal et al., 2015), which used to predict related microRNAs, showed no validated sequences for IRBP gene, but several predicted sequences. Predicted IRBPrelated microRNAs have been studied in previous retinal studies, as shown in Table 1. Among which, miR-140-3p, miR-210$5 p$ and miR-190b-5p may be of interest in manipulating the expression of IRBP. miR-140-3p participates in RPE cell survival and apoptosis. Loss of circRNA_0084043 depressed high glucose (HG)-induced apoptosis in ARPE-19 cells by upregulating miR140-3p (Li et al., 2020). Given the essential role inflammation plays in retinal degenerations, miRNA that simultaneously maintains normal retinal function and influence inflammatory processes are of key therapeutic interest.

Once such miRNA miR-146a downregulates various genes involved in normal retinal function and homeostasis, including IL-6, IL-8 (Chen et al., 2010; Li et al., 2010) and is also predicted to regulate IRBP. The exploitation of microRNAs involved in modulating IRBP may be of clinical significance.

\section{CRISPRa Gene Therapy}

Since the development of gene-editing techniques such as zincfinger nucleases (ZFNs) and transcription activator-like effector nucleases (TALENs), the third generation, clustered regularly interspaced short palindromic repeats (CRISPR) technique has recently risen (Doudna and Charpentier, 2014). This technique has made gene therapy easier and more specific for targeting a gene of interest, like IRBP. The recent development of CRISPR interference (CRISPRi) and CRISPR activation (CRISPRa) system that fuses dead nuclease Cas9 (dCas9) to a transcriptional complex, enables inhibiting or activating the transcription of target genes rather than cleaving them (Gilbert et al., 2014). CRISPRa technology also can activate multiple genes simultaneously (McCarty et al., 2020). Multiplex modulation through CRISPRa enables more precise and efficient gene editing, as many human diseases result from mutations in multiple genes (Zlotogora, 2007). Human IRBP is $\sim 9.5 \mathrm{~kb}$ in length, which exceeds the standard packing capacity of a virus. This is a significant hurdle to develop gene therapies that target IRBP. We may benefit from boosting the transcription of IRBP through specifically designed guide RNA in the CRISPRa system. Gene therapies using CRISPR technology have already been launched in clinical trials. A patient with a hereditary blindness disorder has become the first to receive a CRISPR/Cas9 gene therapy administered directly into their body recently (Ledford, 2020). Thus, the success of IRBP upregulation using this advanced technology has translational applications. 
TABLE 1 | Correlation of predicted microRNA in regulating IRBP and retinal disease.

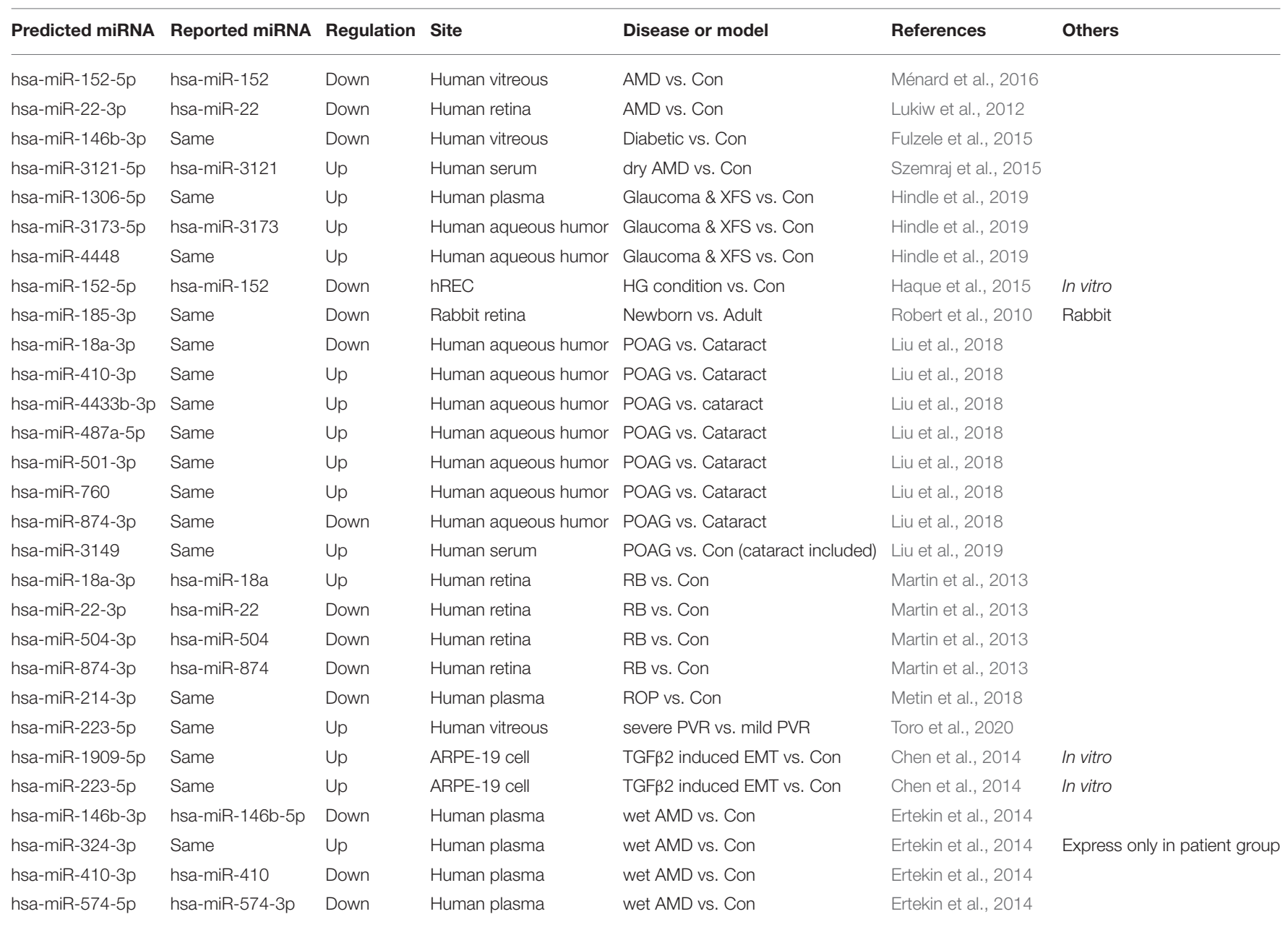

hREC, human retinal endothelial cells; XFS, exfoliation syndrome; Con, control; AMD, age-related macular degeneration; HG, high glucose; RB, retinoblastoma; POAG, primary open-angle glaucoma; EMT, epithelial-mesenchymal transition; ROP, retinopathy of Prematurity; PVR, proliferative vitreoretinopathy.

\section{CONCLUSION AND FUTURE DIRECTIONS}

IRBP is required to maintain the normal functions of the retina, and its downregulation is a common phenomenon at the early stages of photoreceptor degeneration. Although it may be an initial defensive response to retinal stress, the suppression of IRBP is harmful to the health of the photoreceptors in the long term (Figure 1c). The close relationship of IRBP downregulation with early symptoms and retinal disease severity forms the basis of its clinical applications as an early diagnostic marker and therapeutic target for many retinal diseases (Garcia-Ramirez et al., 2009; Zhu et al., 2015; Yokomizo et al., 2019). It is expected that restoring the expression of IRBP may slow the degeneration of photoreceptors. Future research involving techniques like CRISPRa-based gene therapy will allow for further exploration of the clinical potential of treating retinal diseases with IRBPtargeted gene therapy.

\section{AUTHOR CONTRIBUTIONS}

TZ and LZ conceived the perspective of the work. SZ, TZ, YC, $\mathrm{LH}$, and MP searched and summarized the literature. SZ and TZ drafted the manuscript. TZ, RA-B, LZ, and RN designed the figure. $M G, N F, R N, F Z$, and $M M$ critically revised the article. All authors commented on and contributed to the final manuscript.

\section{FUNDING}

This study was supported by an Australian National Health and Medical Research Council Ideas Grant (APP1188332), grants from the Lowy Medical Research Institute, the Rebecca L. Cooper Medical Research Foundation and the ANU Translational Fellowship. SZ was supported by Merri Borton Scholarship. MG is a Sydney Medical School Fellow and supported by an Australian National Health and Medical Research Council Practitioner Fellowship. 


\section{REFERENCES}

Adler, A. J., and Evans, C. D. (1983). Rapid isolation of bovine interphotoreceptor retinol-binding protein. Biochim. Biophys. Acta. 761, 217-222. doi: 10.1016/0304-4165(83)90068-5

Adler, A. J., and Severin, K. M. (1981). Proteins of the bovine interphotoreceptor matrix: tissues of origin. Exp. Eye Res. 32, 755-769. doi: 10.1016/0014-4835(81)90025-7

Agarwal, R. K., Silver, P. B., and Caspi, R. R. (2012). Rodent models of experimental autoimmune uveitis. Methods Mol. Biol. 900, 443-469. doi: 10.1007/978-1-60761-720-4_22

Agarwal, V., Bell, G. W., Nam, J. W., and Bartel, D. P. (2015). Predicting effective microRNA target sites in mammalian mRNAs. eLife 4:e05005. doi: $10.7554 /$ eLife. 05005

Ambros, V. (2004). The functions of animal microRNAs. Nature 431, 350-355. doi: $10.1038 /$ nature 02871

Arno, G., Hull, S., Robson, A. G., Holder, G. E., Cheetham, M. E., Webster, A. R., et al. (2015). Lack of interphotoreceptor retinoid binding protein caused by homozygous mutation of RBP3 is associated with high myopia and retinal dystrophy. Invest. Ophthalmol. Vis. Sci. 56, 2358-2365. doi: $10.1167 /$ iovs. $15-16520$

Bartel, D. P. (2018). Metazoan microRNAs. Cell 173, 20-51. doi: 10.1016/j.cell.2018.03.006

Benhar, I., London, A., and Schwartz, M. (2012). The privileged immunity of immune privileged organs: the case of the eye. Front. Immunol. 3:296. doi: 10.3389/fimmu.2012.00296

Betts-Obregon, B. S., Gonzalez-Fernandez, F., and Tsin, A. T. (2014). Interphotoreceptor retinoid-binding protein (IRBP) promotes retinol uptake and release by rat Müller cells (rMC-1) in vitro: implications for the cone visual cycle. Invest. Ophthalmol. Vis. Sci. 55, 6265-6271. doi: 10.1167/iovs.14-14721

Birnbach, C. D., Jarvelainen, M., Possin, D. E., and Milam, A. H. (1994). Histopathology and immunocytochemistry of the neurosensory retina in fundus flavimaculatus. Ophthalmology 101, 1211-1219. doi: 10.1016/S0161-6420(13)31725-4

Blackshaw, S., and Snyder, S. H. (1997). Parapinopsin, a novel catfish opsin localized to the parapineal organ, defines a new gene family. J. Neurosci. 17, 8083-8092. doi: 10.1523/JNEUROSCI.17-21-08083.1997

Bobola, N., Briata, P., Ilengo, C., Rosatto, N., Craft, C., Corte, G., et al. (1999). OTX2 homeodomain protein binds a DNA element necessary for interphotoreceptor retinoid binding protein gene expression. Mech. Dev. 82, 165-169. doi: 10.1016/S0925-4773(98)00162-2

Buddingh, B. C., Elzinga, J., and van Hest, J. C. M. (2020). Intercellular communication between artificial cells by allosteric amplification of a molecular signal. Nat. Commun. 11, 1652. doi: 10.1038/s41467-020-15482-8

Carlson, A., and Bok, D. (1992). Promotion of the release of 11-cis-retinal from cultured retinal pigment epithelium by interphotoreceptor retinoid-binding protein. Biochemistry 31, 9056-9062. doi: 10.1021/bi00152a049

Carrasquillo, K. G., Ricker, J. A., Rigas, I. K., Miller, J. W., Gragoudas, E. S., and Adamis, A. P. (2003). Controlled delivery of the anti-VEGF aptamer EYE001 with poly(lactic-co-glycolic)acid microspheres. Invest. Ophthalmol. Vis. Sci. 44, 290-299. doi: 10.1167/iovs.01-1156

Caspi, R. R., Chan, C. C., Wiggert, B., and Chader, G. J. (1990). The mouse as a model of experimental autoimmune uveoretinitis (EAU). Curr. Eye Res. 9, 169-174. doi: 10.3109/02713689008999438

Chan, T., Zhu, L., Madigan, M. C., Wang, K., Shen, W., Gillies, M. C., et al. (2015). Human organic anion transporting polypeptide 1A2 (OATP1A2) mediates cellular uptake of all-trans-retinol in human retinal pigmented epithelial cells. Br. J. Pharmacol. 172, 2343-2353. doi: 10.1111/bph.13060

Chen, C., Adler, L.t, Goletz, P., Gonzalez-Fernandez, F., Thompson, D. A., and Koutalos, Y. (2017). Interphotoreceptor retinoid-binding protein removes all-trans-retinol and retinal from rod outer segments, preventing lipofuscin precursor formation. J. Biol. Chem. 292, 19356-19365. doi: 10.1074/jbc.M117.795187

Chen, L. H., Chiou, G. Y., Chen, Y. W., Li, H. Y., and Chiou, S. H. (2010). MicroRNA and aging: a novel modulator in regulating the aging network. Ageing Res. Rev. 9(Suppl. 1), S59-S66. doi: 10.1016/j.arr.2010.08.002
Chen, M., Luo, C., Zhao, J., Devarajan, G., and Xu, H. (2019). Immune regulation in the aging retina. Prog. Retin. Eye Res. 69, 159-172. doi: 10.1016/j.preteyeres.2018.10.003

Chen, X., Ye, S., Xiao, W., Luo, L., and Liu, Y. (2014). Differentially expressed microRNAs in TGFbeta2-induced epithelial-mesenchymal transition in retinal pigment epithelium cells. Int. J. Mol. Med. 33, 1195-1200. doi: $10.3892 /$ ijmm.2014.1688

Chen, Y., Okano, K., Maeda, T., Chauhan, V., Golczak, M., Maeda, A., et al. (2012). Mechanism of all-trans-retinal toxicity with implications for stargardt disease and age-related macular degeneration. J. Biol. Chem. 287, 5059-5069. doi: $10.1074 /$ jbc.M111.315432

Chen, Y., Saari, J. C., and Noy, N. (1993). Interactions of all-trans-retinol and long-chain fatty acids with interphotoreceptor retinoid-binding protein. Biochemistry 32, 11311-11318. doi: 10.1021/bi00093a007

Coelho, T., Adams, D., Silva, A., Lozeron, P., Hawkins, P. N., Mant, T., et al. (2013). Safety and efficacy of RNAi therapy for transthyretin amyloidosis. N. Engl. J. Med. 369, 819-829. doi: 10.1056/NEJMoa1208760

Cook, J. D., Ng, S. Y., Lloyd, M., Eddington, S., Sun, H., Nathans, J., et al. (2017). Peropsin modulates transit of vitamin A from retina to retinal pigment epithelium. J. Biol. Chem. 292, 21407-21416. doi: 10.1074/jbc.M117.812701

Craft, C. M., Whitmore, D. H., and Wiechmann, A. F. (1994). Cone arrestin identified by targeting expression of a functional family. J. Biol. Chem. 269, 4613-4619.

Crouch, R. K., Hazard, E. S., Lind, T., Wiggert, B., Chader, G., and Corson, D. W. (1992). Interphotoreceptor retinoid-binding protein and alpha-tocopherol preserve the isomeric and oxidation state of retinol. Photochem. Photobiol. 56, 251-255. doi: 10.1111/j.1751-1097.1992.tb02154.x

Das, S. R., Bhardwaj, N., Kjeldbye, H., and Gouras, P. (1992). Muller cells of chicken retina synthesize 11-cis-retinol. Biochem. J. 285, 907-913. doi: $10.1042 /$ bj2850907

den Hollander, A. I., McGee, T. L., Ziviello, C., Banfi, S., Dryja, T. P., GonzalezFernandez, F., et al. (2009). A homozygous missense mutation in the IRBP gene (RBP3) associated with autosomal recessive retinitis pigmentosa. Invest. Ophthalmol. Vis. Sci. 50, 1864-1872. doi: 10.1167/iovs.08-2497

Doudna, J. A., and Charpentier, E. (2014). Genome editing. The new frontier of genome engineering with CRISPR-Cas9. Science 346:1258096. doi: 10.1126/science.1258096

Ertekin, S., Yildirim, O., Dinç E., Ayaz, L., Fidanci S. B., and Tamer, L. (2014). Evaluation of circulating miRNAs in wet age-related macular degeneration. Mol. Vis. 20, 1057-1066.

Fei, Y., Matragoon, S., Smith, S. B., Overbeek, P. A., Chen, S., Zack, D. J., et al. (1999). Functional dissection of the promoter of the interphotoreceptor retinoid-binding protein gene: the cone-rod-homeobox element is essential for photoreceptor-specific expression in vivo. J. Biochem. 125, 1189-1199. doi: 10.1093/oxfordjournals.jbchem.a022403

Filipowicz, W., Bhattacharyya, S. N., and Sonenberg, N. (2008). Mechanisms of post-transcriptional regulation by microRNAs: are the answers in sight? Nat. Rev. Genetics 9, 102-114. doi: 10.1038/nrg2290

Friedman, R. C., Farh, K. K., Burge, C. B., and Bartel, D. P. (2009). Most mammalian mRNAs are conserved targets of microRNAs. Genome Res. 19, 92-105. doi: 10.1101/gr.082701.108

Fulzele, S., El-Sherbini, A., Ahmad, S., Sangani, R., Matragoon, S., El-Remessy, A., et al. (2015). MicroRNA-146b-3p regulates retinal inflammation by suppressing adenosine deaminase-2 in diabetes. Biomed Res. Int. 2015:846501. doi: $10.1155 / 2015 / 846501$

Garcia-Ramirez, M., Hernandez, C., Villarroel, M., Canals, F., Alonso, M. A., Fortuny, R., et al. (2009). Interphotoreceptor retinoid-binding protein (IRBP) is downregulated at early stages of diabetic retinopathy. Diabetologia 52, 2633-2641. doi: 10.1007/s00125-009-1548-8

Garlipp, M. A., and Gonzalez-Fernandez, F. (2013). Cone outer segment and Müller microvilli pericellular matrices provide binding domains for interphotoreceptor retinoid-binding protein (IRBP). Exp. Eye Res. 113, 192-202. doi: 10.1016/j.exer.2013.02.003

Ghosh, D., Haswell, K. M., Sprada, M., and Gonzalez-Fernandez, F. (2015). Structure of zebrafish IRBP reveals fatty acid binding. Exp. Eye Res. 140, 149-158. doi: 10.1016/j.exer.2015.08.026 
Gibbs, E., Matsubara, J., Cao, S., Cui, J., and Forooghian, F. (2017). Antigenspecificity of antiretinal antibodies in patients with noninfectious uveitis. Can. J. Ophthalmol. 52, 463-467. doi: 10.1016/j.jcjo.2017.03.010

Gilbert, L. A., Horlbeck, M. A., Adamson, B., Villalta, J. E., Chen, Y., Whitehead, E. H., et al. (2014). Genome-scale CRISPR-mediated control of gene repression and activation. Cell 159, 647-661. doi: 10.1016/j.cell.2014.09.029

Goldberg, A. F., Moritz, O. L., and Williams, D. S. (2016). Molecular basis for photoreceptor outer segment architecture. Prog. Retin. Eye Res. 55, 52-81. doi: $10.1016 /$ j.preteyeres.2016.05.003

Gonzalez-Fernandez, F. (2003). Interphotoreceptor retinoid-binding protein-an old gene for new eyes. Vis. Res. 43, 3021-3036. doi: 10.1016/j.visres.2003.09.019

Gonzalez-Fernandez, F. (2012). Interphotoreceptor retinoid binding protein; myths and mysteries. J. Ophthalmic Vis. Res. 7, 100-104.

Gonzalez-Fernandez, F., and Ghosh, D. (2008). Focus on molecules: interphotoreceptor retinoid-binding protein (IRBP). Exp. Eye Res. 86, 169-170. doi: 10.1016/j.exer.2006.09.003

Gonzalez-Fernandez, F., Sung, D., Haswell, K. M., Tsin, A., and Ghosh, D. (2014). Thiol-dependent antioxidant activity of interphotoreceptor retinoid-binding protein. Exp. Eye Res. 120, 167-174. doi: 10.1016/j.exer.2014.01.002

Gonzalez-Fernandez, F., van Niel, E., Edmonds, C., Beaver, H., Nickerson, J. M., Garcia-Fernandez, J. M., et al. (1993). Differential expression of interphotoreceptor retinoid-binding protein, opsin, cellular retinaldehydebinding protein, and basic fibroblastic growth factor. Exp. Eye Res. 56, 411-427. doi: 10.1006/exer.1993.1055

Haque, R., Hur, E. H., Farrell, A. N., Iuvone, P. M., and Howell, J. C. (2015). MicroRNA-152 represses VEGF and TGFbetal expressions through posttranscriptional inhibition of (Pro)renin receptor in human retinal endothelial cells. Mol. Vis. 21, 224-235.

He, L., and Hannon, G. J. (2004). MicroRNAs: small RNAs with a big role in gene regulation. Nat. Rev. Genetics 5, 522-531. doi: 10.1038/nrg1379

Hessler, R. B., Baer, C. A., Bukelman, A., Kittredge, K. L., and Gonzalez-Fernandez, F. (1996). Interphotoreceptor retinoid-binding protein (IRBP): expression in the adult and developing Xenopus retina. J. Comp. Neurol. 367, 329-341. doi: 10.1002/(SICI)1096-9861(19960408)367:3<329::AID-CNE1>3.0.CO;2-7

Hindle, A. G., Thoonen, R., Jasien, J. V., Grange, R. M. H., Amin, K., Wise, J., et al. (2019). Identification of candidate miRNA biomarkers for glaucoma. Invest. Ophthalmol. Vis. Sci. 60, 134-146. doi: 10.1167/iovs.18-24878

Hollyfield, J. G. (1999). Hyaluronan and the functional organization of the interphotoreceptor matrix. Invest. Ophthalmol. Vis. Sci. 40, 2767-2769.

Ishikawa, M., Sawada, Y., and Yoshitomi, T. (2015). Structure and function of the interphotoreceptor matrix surrounding retinal photoreceptor cells. Exp. Eye Res. 133, 3-18. doi: 10.1016/j.exer.2015.02.017

Jastrzebska, B., Debinski, A., Filipek, S., and Palczewski, K. (2011). Role of membrane integrity on $\mathrm{G}$ protein-coupled receptors: rhodopsin stability and function. Prog. Lipid Res. 50, 267-277. doi: 10.1016/j.plipres.2011. 03.002

Jin, M., Li, S., Nusinowitz, S., Lloyd, M., Hu, J., Radu, R. A., et al. (2009). The role of interphotoreceptor retinoid-binding protein on the translocation of visual retinoids and function of cone photoreceptors. J. Neurosci. 29, 1486-1495. doi: 10.1523/JNEUROSCI.3882-08.2009

Jones, G. J., Crouch, R. K., Wiggert, B., Cornwall, M. C., and Chader, G. J. (1989). Retinoid requirements for recovery of sensitivity after visual-pigment bleaching in isolated photoreceptors. Proc. Natl. Acad. Sci. U.S.A. 86, 9606-9610. doi: $10.1073 /$ pnas.86.23.9606

Kennedy, B. N., Alvarez, Y., Brockerhoff, S. E., Stearns, G. W., Sapetto-Rebow, B., Taylor, M. R., et al. (2007). Identification of a zebrafish cone photoreceptorspecific promoter and genetic rescue of achromatopsia in the nof mutant. Invest. Ophthalmol. Vis. Sci. 48, 522-529. doi: 10.1167/iovs.06-0975

Kiser, P. D., Golczak, M., and Palczewski, K. (2014). Chemistry of the retinoid (visual) cycle. Chem. Rev. 114, 194-232. doi: 10.1021/cr400107q

Kompella, U. B., Bandi, N., and Ayalasomayajula, S. P. (2003). Subconjunctival nano- and microparticles sustain retinal delivery of budesonide, a corticosteroid capable of inhibiting VEGF expression. Invest. Ophthalmol. Vis. Sci. 44, 1192-1201. doi: 10.1167/iovs.02-0791

Kusakabe, T. G., Takimoto, N., Jin, M., and Tsuda, M. (2009). Evolution and the origin of the visual retinoid cycle in vertebrates. Philos. Trans. $R$ Soc. London Series B Biol. Sci. 364, 2897-2910. doi: 10.1098/rstb.2009. 0043
Kyger, M., Worley, A., and Adamus, G. (2013). Autoimmune responses against photoreceptor antigens during retinal degeneration and their role in macrophage recruitment into retinas of RCS rats. J. Neuroimmunol. 254, 91-100. doi: 10.1016/j.jneuroim.2012. 10.007

Ledford, H. (2020). CRISPR treatment inserted directly into the body for first time. Nature 579:185. doi: 10.1038/d41586-020-00655-8

Lee, M., Li, S., Sato, K., and Jin, M. (2016). Interphotoreceptor retinoid-binding protein mitigates cellular oxidative stress and mitochondrial dysfunction induced by all-trans-retinal. Invest. Ophthalmol. Vis. Sci. 57, 1553-1562. doi: 10.1167/iovs.15-18551

Lee, R. C., Feinbaum, R. L., and Ambros, V. (1993). The C. elegans heterochronic gene lin-4 encodes small RNAs with antisense complementarity to lin-14. Cell 75, 843-854. doi: 10.1016/0092-8674(93)90529-Y

Li, G., Luna, C., Qiu, J., Epstein, D. L., and Gonzalez, P. (2010). Modulation of inflammatory markers by miR-146a during replicative senescence in trabecular meshwork cells. Invest. Ophthalmol. Vis. Sci. 51, 2976-2985. doi: 10.1167/iovs.09-4874

Li, S., Yang, Z., Hu, J., Gordon, W. C., Bazan, N. G., Haas, A. L., et al. (2013). Secretory defect and cytotoxicity: the potential disease mechanisms for the retinitis pigmentosa (RP)-associated interphotoreceptor retinoid-binding protein (IRBP). J. Biol. Chem. 288, 11395-11406. doi: 10.1074/jbc.M112.418251

Li, W. H., Zhou, L., Li, Z., Wang, Y., Shi, J. T., Yang, Y. J., et al. (2015). Zebrafish Lbh-like is required for Otx2-mediated photoreceptor differentiation. Int. J. Biol. Sci. 11, 688-700. doi: 10.7150/ijbs.11244

Li, Y., Cheng, T., Wan, C., and Cang, Y. (2020). circRNA_0084043 contributes to the progression of diabetic retinopathy via sponging miR-140-3p and inducing TGFA gene expression in retinal pigment epithelial cells. Gene 747:144653. doi: 10.1016/j.gene.2020.144653

Liou, G. I., Bridges, C. D., Fong, S. L., Alvarez, R. A., and Gonzalez-Fernandez, F. (1982). Vitamin A transport between retina and pigment epithelium-an interstitial protein carrying endogenous retinol (interstitial retinol-binding protein). Vis. Res. 22, 1457-1467. doi: 10.1016/0042-6989(82)90210-3

Liou, G. I., Fei, Y., Peachey, N. S., Matragoon, S., Wei, S., Blaner, W. S., et al. (1998). Early onset photoreceptor abnormalities induced by targeted disruption of the interphotoreceptor retinoid-binding protein gene. J. Neurosci. 18, 4511-4520. doi: 10.1523/JNEUROSCI.18-12-04511.1998

Liou, G. I., Wang, M., and Matragoon, S. (1994). Timing of interphotoreceptor retinoid-binding protein (IRBP) gene expression and hypomethylation in developing mouse retina. Dev. Biol. 161, 345-356. doi: 10.1006/dbio.1994.1036

Liu, A., Chang, J., Lin, Y., Shen, Z., and Bernstein, P. S. (2010). Long-chain and very long-chain polyunsaturated fatty acids in ocular aging and age-related macular degeneration. J. Lipid Res. 51, 3217-3229. doi: 10.1194/jlr.M007518

Liu, Y. M., Chen, Y., Wang, Y. Y., Zhang, X. Y., Gao, K., Chen, S. D., et al. (2018). microRNA profiling in glaucoma eyes with varying degrees of optic neuropathy by using next-generation sequencing. Invest. Ophthalmol. Vis. Sci. 59, 2955-2966. doi: 10.1167/iovs.17-23599

Liu, Y. M., Wang, Y. Y., Chen, Y., Fang, X. L., Wen, T., Xiao, M. L., et al. (2019). Discovery and validation of circulating Hsa-miR-210-3p as a potential biomarker for primary open-angle glaucoma. Invest. Ophthalmol. Vis. Sci. 60, 2925-2934. doi: 10.1167/iovs.19-26663

Lukiw, W. J., Surjyadipta, B., Dua, P., and Alexandrov, P. N. (2012). Common micro RNAs (miRNAs) target complement factor $\mathrm{H}(\mathrm{CFH})$ regulation in Alzheimer's disease (AD) and in age-related macular degeneration (AMD). Int. J. Biochem. Mol. Biol. 3, 105-116.

Maeda, A., Maeda, T., Golczak, M., Chou, S., Desai, A., Hoppel, C. L., et al. (2009). Involvement of all-trans-retinal in acute light-induced retinopathy of mice. J. Biol. Chem. 284, 15173-15183. doi: 10.1074/jbc.M900322200

Malechka, V. V., Moiseyev, G., Takahashi, Y., Shin, Y., and Ma, J. X. (2017). Impaired rhodopsin generation in the rat model of diabetic retinopathy. Am. J. Pathol. 187, 2222-2231. doi: 10.1016/j.ajpath.2017.06.007

Markand, S., Baskin, N. L., Chakraborty, R., Landis, E., Wetzstein, S. A., Donaldson, K. J., et al. (2016). IRBP deficiency permits precocious ocular development and myopia. Mol. Vis. 22, 1291-1308.

Marmorstein, A. D., Marmorstein, L. Y., Sakaguchi, H., and Hollyfield, J. G. (2002). Spectral profiling of autofluorescence associated with lipofuscin, Bruch's membrane, and sub-RPE deposits in normal and AMD eyes. Invest. Ophthalmol. Vis. Sci. 43, 2435-2441. 
Martin, J., Bryar, P., Mets, M., Weinstein, J., Jones, A., Martin, A., et al. (2013). Differentially expressed miRNAs in retinoblastoma. Gene 512, 294-299. doi: 10.1016/j.gene.2012.09.129

Mata, N. L., Radu, R. A., Clemmons, R. C., and Travis, G. H. (2002), Isomerization and oxidation of vitamin a in cone-dominant retinas: a novel pathway for visual-pigment regeneration in daylight. Neuron 36, 69-80. doi: 10.1016/S0896-6273(02)00912-1

Maxim, L. D., Niebo, R., and Utell, M. J. (2014). Screening tests: a review with examples. Inhal. Toxicol. 26, 811-828. doi: 10.3109/08958378.2014.955932

McCarty, N. S., Graham, A. E., Studen,á L., and Ledesma-Amaro, R. (2020). Multiplexed CRISPR technologies for gene editing and transcriptional regulation. Nat. Commun. 11:1281. doi: 10.1038/s41467-020-15053-X

McDougald, D. S., Duong, T. T., Palozola, K. C., Marsh, A., Papp, T. E., Mills, J. A., et al. (2019). CRISPR activation enhances in vitro potency of AAV vectors driven by tissue-specific promoters. Mol. Ther. Methods Clin. Dev. 13, 380-389. doi: 10.1016/j.omtm.2019.03.004

Ménard, C., Rezende, F. A., Miloudi, K., Wilson, A., Tétreault, N., Hardy, P., et al. (2016). MicroRNA signatures in vitreous humour and plasma of patients with exudative AMD. Oncotarget 7, 19171-19184. doi: 10.18632/oncotarget.8280

Menotti-Raymond, M., David, V. A., Schaffer, A. A., Stephens, R., Wells, D., Kumar-Singh, R., et al. (2007). Mutation in CEP290 discovered for cat model of human retinal degeneration. J. Hered. 98, 211-220. doi: 10.1093/jhered/esm019

Metin, T., Din,ç E., Görür, A., Erdogan, S., Ertekin, S., Sar,i A. A., et al. (2018). Evaluation of the plasma microRNA levels in stage 3 premature retinopathy with plus disease: preliminary study. Eye 32, 415-420. doi: 10.1038 /eye. 2017.193

Miraglia, L. J., King, F. J., and Damoiseaux, R. (2011). Seeing the light: luminescent reporter gene assays. Comb. Chem. High Throughput Screen. 14, 648-657. doi: 10.2174/138620711796504389

Molday, R. S., and Moritz, O. L. (2015). Photoreceptors at a glance. J. Cell Sci. 128, 4039-4045. doi: 10.1242/jcs. 175687

Morohoshi, K., Ohbayashi, M., Patel, N., Chong, V., Bird, A. C., and Ono, S. J. (2012). Identification of anti-retinal antibodies in patients with age-related macular degeneration. Exp. Mol. Pathol. 93, 193-199. doi: 10.1016/j.yexmp.2012.03.007

Narfstrom, K., Nilsson, S. E., Wiggert, B., Lee, L., Chader, G. J., and van Veen, T. (1989). Reduced level of interphotoreceptor retinoid-binding protein (IRBP), a possible cause for retinal degeneration in the Abyssinian cat. Cell Tissue Res. 257, 631-639. doi: 10.1007/BF00221474

Nickerson, J. M., Frey, R. A., Ciavatta, V. T., and Stenkamp, D. L. (2006). Interphotoreceptor retinoid-binding protein gene structure in tetrapods and teleost fish. Mol. Vis. 12, 1565-1585.

Nishida, A., Furukawa, A., Koike, C., Tano, Y., Aizawa, S., Matsuo, I., et al. (2003). Otx2 homeobox gene controls retinal photoreceptor cell fate and pineal gland development. Nat. Neurosci. 6, 1255-1263. doi: 10.1038/nn1155

Parker, R., Wang, J. S., Kefalov, V. J., and Crouch, R. K. (2011). Interphotoreceptor retinoid-binding protein as the physiologically relevant carrier of 11-cis-retinol in the cone visual cycle. J. Neurosci. 31, 4714-4719. doi: 10.1523/JNEUROSCI.3722-10.2011

Parker, R. O., and Crouch, R. K. (2010). The interphotoreceptor retinoid binding (IRBP) is essential for normal retinoid processing in cone photoreceptors. Adv. Exp. Med. Biol. 664, 141-149. doi: 10.1007/978-1-4419-1399-9_17

Purves, D. A. G., and Fitzpatrick, D. (2001). Strategies of Molecular Signaling. Neuroscience. 2nd Edn. Sunderland, MA: Sinauer Associates, Inc.

Radu, R. A., Mata, N. L., Nusinowitz, S., Liu, X. R., Sieving, P. A., and Travis, G. H. (2003). Treatment with isotretinoin inhibits lipofuscin accumulation in a mouse model of recessive Stargardt's macular degeneration. Proc. Natl. Acad. Sci. U.S.A. 100, 4742-4747. doi: 10.1073/pnas.0737855100

Riley, M. K., and Vermerris, W. (2017). Recent advances in nanomaterials for gene delivery-a review. Nanomaterials 7:94. doi: 10.3390/nano7050094

Rizk, M., and Tuzmen, S. (2017). Update on the clinical utility of an RNA interference-based treatment: focus on Patisiran. Pharmgenomics. Pers. Med. 10, 267-278. doi: 10.2147/PGPM.S87945

Robert, E., Anderson, J. G. H., and Matthew, M. (2010). Retinal Degenerative Disease. Advances in Experimental Medicine and Biology, Vol. 664 (Springer Science \& Bussiness Media), 206-208. Available online at: https://books.google.com.au/books?id=1x_NTfV6xlAC\&pg=PA207dq=miR-18 $5+$ retina\&source $=$ bl\&ots $=7 \mathrm{oIO} 8 \mathrm{o} 0 \mathrm{fmV} \& \mathrm{sig}=\mathrm{ACfU} 3 \mathrm{U} 1 \mathrm{aSP} 6 \_\mathrm{X} \_7$ E5WAetoxt $\mathrm{dm}-3 \mathrm{H} 8 \mathrm{Q}$ sew\&hl=en\&sa=X\&ved=2ahUKEwiftby6loXqAhUkxDgGHQKvAc 8Q6AEwA3oECAoQAQ\#v=onepage $\& \mathrm{q}=$ miR-185\%20retina $\& \mathrm{f}=$ false

Rodrigues, M. M., Hackett, J., Gaskins, R., Wiggert, B., Lee, L., Redmond, M., et al. (1986). Interphotoreceptor retinoid-binding protein in retinal rod cells and pineal gland. Invest. Ophthalmol. Vis. Sci. 27, 844-850.

Rózanowska, M., Handzel, K., Boulton, M. E., and Rózanowski, B. (2012). Cytotoxicity of all-trans-retinal increases upon photodegradation. Photochem. Photobiol. 88, 1362-1372. doi: 10.1111/j.1751-1097.2012.01161.x

Sapède, D., and Cau, E. (2013). The pineal gland from development to function. Curr. Top. Dev. Biol. 106, 171-215. doi: 10.1016/B978-0-12-416021-7. 00005-5

Sato, K., Li, S., Gordon, W. C., He, J., Liou, G. I., Hill, J. M., et al. (2013). Receptor interacting protein kinase-mediated necrosis contributes to cone and rod photoreceptor degeneration in the retina lacking interphotoreceptor retinoid-binding protein. J. Neurosci. 33, 17458-17468. doi: 10.1523/JNEUROSCI.1380-13.2013

Sato, S., and Kefalov, V. J. (2016). cis Retinol oxidation regulates photoreceptor access to the retina visual cycle and cone pigment regeneration. J. Physiol. 594, 6753-6765. doi: 10.1113/JP272831

Scott, B. L., and Bazan, N. G. (1989). Membrane docosahexaenoate is supplied to the developing brain and retina by the liver. Proc. Natl. Acad. Sci. U.S.A. 86, 2903-2907. doi: 10.1073/pnas.86.8.2903

Semenova, E. M., and Converse, C. A. (2003). Comparison between oleic acid and docosahexaenoic acid binding to interphotoreceptor retinoid-binding protein. Vis. Res. 43, 3063-3067. doi: 10.1016/j.visres.2003.09.008

Solomon, A., Banin, E., Anteby, I., and Benezra, D. (1999). Retinitis pigmentosa, coats disease and uveitis. Eur. J. Ophthalmol. 9, 202-205. doi: 10.1177/112067219900900307

Soundara Pandi, S. P., Chen, M., Guduric-Fuchs, J., Xu, H., and Simpson, D. A. (2013). Extremely complex populations of small RNAs in the mouse retina and RPE/choroid. Invest. Ophthalmol. Vis. Sci. 54, 8140-8151. doi: 10.1167/iovs.13-12631

Stenkamp, D. L., Cunningham, L. L., Raymond, P. A., and Gonzalez-Fernandez, F. (1998). Novel expression pattern of interphotoreceptor retinoid-binding protein (IRBP) in the adult and developing zebrafish retina and RPE. Mol. Vis. $4: 26$.

Szemraj, M., Bielecka-Kowalska, A., Oszajca, K., Krajewska, M., Go,ś R., Jurowski, P., et al. (2015). Serum microRNAs as potential biomarkers of AMD. Med. Sci. Monit. 21, 2734-2742. doi: 10.12659/MSM.893697

Tang, P. H., Kono, M., Koutalos, Y., Ablonczy, Z., and Crouch, R. K. (2013). New insights into retinoid metabolism and cycling within the retina. Prog. Retin. Eye Res. 32, 48-63. doi: 10.1016/j.preteyeres.2012.09.002

Timmers, A. M., Newton, B. R., and Hauswirth, W. W. (1993). Synthesis and stability of retinal photoreceptor mRNAs are coordinately regulated during bovine fetal development. Exp. Eye Res. 56, 257-265. doi: 10.1006/exer.1993.1034

Toro, M. D., Reibaldi, M., Avitabile, T., Bucolo, C., Salomone, S., Rejdak, R., et al. (2020). MicroRNAs in the vitreous humor of patients with retinal detachment and a different grading of proliferative vitreoretinopathy: a pilot study. Transl. Vis. Sci. Technol. 9:23 doi: 10.1167/tvst.9.6.23

van Veen, T., Katial, A., Shinohara, T., Barrett, D. J., Wiggert, B., Chader, G. J., et al. (1986). Retinal photoreceptor neurons and pinealocytes accumulate mRNA for interphotoreceptor retinoid-binding protein (IRBP). FEBS Lett. 208, 133-137. doi: 10.1016/0014-5793(86)81547-2

Vecino, E., Rodriguez, F. D., Ruzafa, N., Pereiro, X., and Sharma, S. C. (2016). Glianeuron interactions in the mammalian retina. Prog. Retin. Eye Res. 51, 1-40. doi: $10.1016 /$ j.preteyeres.2015.06.003

Wald, G. (1935). Carotenoids and the visual cycle. J. Gen. Physiol. 19, 351-371. doi: 10.1085/jgp.19.2.351

Wang, J. S., and Kefalov, V. J. (2009). An alternative pathway mediates the mouse and human cone visual cycle. Curr. Biol. 19, 1665-1669. doi: 10.1016/j.cub.2009.07.054

Wang, K., Zhu, X., Zhang, K., Zhou, F., and Zhu, L. (2017). Neuroprotective effect of tetramethylpyrazine against all-trans-retinal toxicity in the differentiated Y-79 cells via upregulation of IRBP expression. Exp. Cell Res. 359, 120-128. doi: 10.1016/j.yexcr.2017.08.002

Wiggert, B., van Veen, T., Kutty, G., Lee, L., Nickerson, J., Si, J. S., et al. (1994). An early decrease in interphotoreceptor retinoid-binding 
protein gene expression in Abyssinian cats homozygous for hereditary rodcone degeneration. Cell Tissue Res. 278, 291-298. doi: 10.1007/s0044100 50220

Wightman, B., Ha, I., and Ruvkun, G. (1993). Posttranscriptional regulation of the heterochronic gene lin-14 by lin- 4 mediates temporal pattern formation in $C$. elegans. Cell 75, 855-862. doi: 10.1016/0092-8674(93)90530-4

Wisard, J., Faulkner, A., Chrenek, M. A., Waxweiler, T., Waxweiler, W., Donmoyer, C., et al. (2011). Exaggerated eye growth in IRBP-deficient mice in early development. Invest. Ophthalmol. Vis. Sci. 52, 5804-5811. doi: 10.1167/iovs.10-7129

Wong, P., Ulyanova, T., Organisciak, D. T., Bennett, S., Lakins, J., Arnold, J. M., et al. (2001). Expression of multiple forms of clusterin during light-induced retinal degeneration. Curr. Eye Res. 23, 157-165. doi: $10.1076 /$ ceyr.23.3.157.5463

Xie, W., Silvers, R., Ouellette, M., Wu, Z., Lu, Q., Li, H., et al. (2016). A luciferase reporter gene system for high-throughput screening of gamma-globin gene activators. Methods Mol. Biol. 1439, 207-226. doi: 10.1007/978-1-4939-3673-1_14

Yokomizo, H., Maeda, Y., Park, K., Clermont, A. C., Hernandez, S. L., Fickweiler, W., et al. (2019). Retinol binding protein 3 is increased in the retina of patients with diabetes resistant to diabetic retinopathy. Sci. Transl. Med. 11:eaau6627. doi: 10.1126/scitranslmed.aau6627

Zhang, T., Gillies, M., Wang, Y., Shen, W., Bahrami, B., Zeng, S., et al. (2019). Simvastatin protects photoreceptors from oxidative stress induced by all-trans-retinal, through the up-regulation of interphotoreceptor retinoid binding protein. Br. J. Pharmacol. 176, 2063-2078. doi: 10.1111/bph. 14650

Zhao, Y., Liu, Y., and Chen, K. (2016). Mechanisms and clinical application of tetramethylpyrazine (an interesting natural compound isolated from Ligusticum Wallichii): current status and perspective. Oxid. Med. Cell. Longev. 2016:2124638. doi: 10.1155/2016/21 24638

Zheng, Q., Ren, Y., Tzekov, R., Hua, S., Li, M., Pang, J., et al. (2015). iTRAQbased proteomic analysis of visual cycle-associated proteins in RPE of rd12 mice before and after RPE65 gene delivery. J. Ophthalmol. 2015:918473. doi: $10.1155 / 2015 / 918473$

Zhu, L., Shen, W., Lyons, B., Wang, Y., Zhou, F., and Gillies, M. C. (2015). Dysregulation of inter-photoreceptor retinoid-binding protein (IRBP) after induced Muller cell disruption. J. Neurochem. 133, 909-918. doi: 10.1111/jnc.13075

Zhu, L., Shen, W., Zhu, M., Coorey, N. J., Nguyen, A. P., Barthelmes, D., et al. (2013). Anti-retinal antibodies in patients with macular telangiectasia type 2. Invest. Ophthalmol. Vis. Sci. 54, 5675-5683. doi: 10.1167/iovs.13-12050

Zlotogora, J. (2007). Multiple mutations responsible for frequent genetic diseases in isolated populations. Eur. J. Hum. Genet. 15, 272-278. doi: $10.1038 /$ sj.ejhg. 5201760

Conflict of Interest: The authors declare that the research was conducted in the absence of any commercial or financial relationships that could be construed as a potential conflict of interest.

Copyright (c) 2020 Zeng, Zhang, Madigan, Fernando, Aggio-Bruce, Zhou, Pierce, Chen, Huang, Natoli, Gillies and Zhu. This is an open-access article distributed under the terms of the Creative Commons Attribution License (CC BY). The use, distribution or reproduction in other forums is permitted, provided the original author(s) and the copyright owner(s) are credited and that the original publication in this journal is cited, in accordance with accepted academic practice. No use, distribution or reproduction is permitted which does not comply with these terms. 